Article

\title{
Optimal Site Selection of Electric Vehicle Charging Stations Based on a Cloud Model and the PROMETHEE Method
}

\author{
Yunna Wu, Meng Yang *, Haobo Zhang, Kaifeng Chen and Yang Wang \\ School of Economics and Management, North China Electric Power University, Beijing 102206, China; \\ 1101340119@ncepu.edu.cn (Y.W.); Elaine0712@yeah.net (H.Z.); ckfhdchina@126.com (K.C.); \\ wangyang1320218@126.com (Y.W.) \\ * Correspondence: raininmydream@163.com; Tel.: +86-158-1141-6923 \\ Academic Editor: K. T. Chau \\ Received: 28 December 2015; Accepted: 3 February 2016; Published: 3 March 2016
}

\begin{abstract}
The task of site selection for electric vehicle charging stations (EVCS) is hugely important from the perspective of harmonious and sustainable development. However, flaws and inadequacies in the currently used multi-criteria decision making methods could result in inaccurate and irrational decision results. First of all, the uncertainty of the information cannot be described integrally in the evaluation of the EVCS site selection. Secondly, rigorous consideration of the mutual influence between the various criteria is lacking, which is mainly evidenced in two aspects: one is ignoring the correlation, and the other is the unconscionable measurements. Last but not least, the ranking method adopted in previous studies is not very appropriate for evaluating the EVCS site selection problem. As a result of the above analysis, a Preference Ranking Organization Method for Enrichment Evaluations (PROMETHEE) method-based decision system combined with the cloud model is proposed in this paper for EVCS site selection. Firstly, the use of the PROMETHEE method can bolster the confidence and visibility for decision makers. Secondly, the cloud model is recommended to describe the fuzziness and randomness of linguistic terms integrally and accurately. Finally, the Analytical Network Process (ANP) method is adopted to measure the correlation of the indicators with a greatly simplified calculation of the parameters and the steps required.
\end{abstract}

Keywords: charging stations for electric vehicles; site selection; Preference Ranking Organization Method for Enrichment Evaluations (PROMETHEE); Analytical Network Process (ANP); cloud model

\section{Introduction}

Electric vehicles (EVs) are drawing ever more attention on account of their reduction of particulate matter smaller than $2.5 \mu \mathrm{m}\left(\mathrm{PM}_{2.5}\right)$ emissions and high energy efficiency. Facing a situation of severe energy shortages and air pollution, the Chinese government and public are strongly motivated to accelerate the use of EVs, which are expected to provide potential and sustainable transport in the future. At the same time, the construction of the electric vehicle charging stations (EVCS) is picking up speed to ensure the synergetic development of the technology.

The site selection for EVCS is hugely important from the perspective of harmonious and sustainable development. Firstly, the chosen location would have a significant influence on the cost, which could mean the difference between success and failure of the project. Secondly, a wrongly selected site might have an adverse impact on its safety and benefits during normal operations, which would hinder the popularization and application of EVs. The last but not the least, a site failing to meet the demands of the environment would not help protect the environment but harm it instead. Accordingly, the site selection for EVCS is a multi-objective decision making problem. Nevertheless, the current studies on the EV predominantly focus on the following fields: battery management [1-4], 
charging scheduling [5-8], energy consumption [9-12] and the impacts on the power system $[13,14]$ and so on. Up till now, only a few scholars have studied the topic of electric vehicle charging site selection, for instance, You and Hsieh [15] proposed a hybrid heuristic approach to address the selection of EVCS locations, Chung and Kwon [16] formulated a multi-period optimization model based on a flow-refueling location model for strategic charging station location planning, and Guo and Zhao [17] applied a fuzzy TOPSIS method to select the optimal EVCS site.

As described in the previous section, the EVCS site selection is a multi-criteria decision making (MCDM) problem. However, flaws and inadequacies in the normal MCDM methods could give rise to inaccurate and irrational decision results. First of all, the uncertainty of the information cannot be described integrally in the evaluation of the EVCS site selection. Because of the variability and complexity of external environment conditions and the limitation of human cognitive abilities, it is difficult for the experts to quantify the attribute value of EVCS sites with an accurate number. It is more reasonable for the experts to assess the performance of the alternatives in the form of linguistic values, which is more aligned with the way human intelligence and emotional expression work. As a result, there are various studies on the topic of linguistic values, in which fuzzy theory has been involved for a long time. Although fuzzy theory can describe the inaccuracy and fuzziness of linguistic information, it fails to represent the randomness of natural language, which may give rise to decision-making mistakes. Generally speaking, the uncertainty contains randomness and fuzziness, which are the most significant and essential elements [18]. What's more, it's worth mentioning that the randomness and fuzziness in the linguistic information cannot be separated from each other. Ignorance of this rule would result in reduced decision effectiveness.

Secondly, the mutual influence among the criteria lacks rigorous consideration, which is mainly evident in two aspects: one is ignoring the correlations, and the other is unconscionable measurements. To the former aspect of the shortage, the majority of the MCDM methods are based on the connotative hypothesis that the criteria are independent of each other, which goes against the reality of the situation. Owing to the limitations of human cognition and common connections in nature, the decision criteria will inevitably have relationships with each other. As for the latter, despite the consideration of correlations, the measurements lack rationality, and the computation processes get fairly complex, which makes them difficult to popularize in a real world application.

Last but not the least, the ranking methods adopted in previous studies are not very appropriate for evaluating the EVCS site selection problem. Until now, MCDM ranking methods could be divided into two categories: utility theory-based methods and outranking methods. Some popular instances are described in Table 1.

Table 1. Descriptions of MCDM methods.

\begin{tabular}{ccl}
\hline Categories & Methods & \multicolumn{1}{c}{ Descriptions } \\
\hline $\begin{array}{c}\text { Utility theory- } \\
\text { based methods }\end{array}$ & AHP & $\begin{array}{l}\text { (1) The overall values generated by such kind of methods are derived via } \\
\text { aggregation operators, and thus make no sense if different criteria are } \\
\text { combined together, especially when the criteria are conflicting [19]. } \\
\text { 2) These methods could obtain a final ranking of the alternatives but cannot } \\
\text { demonstrate why the alternatives are satisfactory or unsatisfactory, which does } \\
\text { not help ameliorate the unsatisfactory alternatives. }\end{array}$ \\
\hline $\begin{array}{c}\text { Outranking } \\
\text { methods }\end{array}$ & TOPSIS & $\begin{array}{l}\text { The ELECTRE method requires more parameters from decision makers than the } \\
\text { PROMETHEE method [20], with a more tedious calculation process [21], } \\
\text { as well as less transparent results [22] }\end{array}$ \\
\cline { 2 - 4 } & PROMETHEE & $\begin{array}{l}\text { The effectiveness of the PROMETHEE method lies in its solid mathematical basis } \\
\text { and ease of application, which could bolster the confidence and visibility for } \\
\text { decision makers. }\end{array}$ \\
\hline
\end{tabular}

According to above analysis, the PROMETHEE method-based decision system combined with the cloud model is proposed in this paper for the EVCS site selection problem. Firstly, the managers and experts from different academic fields determine the expectations of the EVCS development planning process, select the factors that may have an effect on the EVCS site selection, and put forward the 
potential alternatives. Secondly, the interaction relationships and pair-wise comparisons between various factors are built by the experts. The Analytic Network Process (ANP) method is employed to measure the mutual effects. The experts assess the performance of the alternatives in the form of a linguistic value, which would further be converted into cloud models to integrally describe the uncertainty of the information. Finally, the PROMETHEE method is employed to rank all decision alternatives, and determine the optimal one.

The PROMETHEE method-based decision system combined with the cloud model possesses the characteristic of operability and effectiveness for EVCS site selection. Firstly, the decision system contributes to the versatility and rationalization of the decision results. The use of the PROMETHEE method bolsters the confidence and visibility for the decision makers, owing to its credible mathematical characteristics and its ease of use. The cloud model, which integrates the fuzziness and randomness of linguistic terms in a better way, is recommended to describe the uncertainty of information. The ANP method is adopted to measure the correlation of the indicators, which increases reliability and accuracy of the decision results with a greatly simplified calculation of the parameters and the steps required. Secondly, the decision system illustrates the labor division of different level managers, and the concrete steps of EVCS site selection, which could greatly promote the efficiency of the management, and strengthen the accuracy and feasibility. Both endeavors are helpful to achieving the target that the decision result shows the versatility and reasonableness for EVCS site selection.

The remainder of this paper is divided as follows: Section 2 presents a review of the flaws and inadequacies of the current MCDM methods, and major applications of the methods adopted in this paper. Section 3 clarifies the decision factors that may have an effect on the EVCS site selection, and an evaluation index system is set up. Section 4 illustrates the concrete procedures of EVCS site selection and the responsibility of different level managers. Section 5 uses a case to explain the overall process. Section 6 carries out a comparative analysis and sensitivity analysis. The last section summarizes the whole paper.

\section{Literature Review}

EVCS site selection is a multiple-criteria evaluation problem as it is influenced by various conflicting criteria, which leads to the fact that the decision success depends mainly on the MCDM method used. To be specific, a suitable ranking method, an integrated description of the uncertain information, as well as the rational measurement of the relevant indicators are the three critical factors of a successful decision. In the first place, a suitable ranking method should be selected. The preference ranking organization method for enrichment evaluations (PROMETHEE), first developed by Brans [23], is a popular outranking method, which is well adapted to situations where a limited number of alternatives must be sorted taking several, sometimes conflicting, criteria into account. Compared with other MCDM methods, the effectiveness of PROMETHEE method lies in its solid mathematical basis and ease of application. The PROMETHEE method has been applied successfully in various areas, such as environmental management, logistics and transportation as well as energy management and so on [24]. Likewise, the PROMETHEE method has also gained prominence in the study of site selection problems. For example, PROMETHEE was applied to selecting logistics center locations [25], landfill sites [22,26], as well as plant locations [27].

The next item, the description of the uncertain information, has attracted more and more attention, which predominantly focuses on the qualitative indicators. Owing to the complexity of research objects and the limitations of human understanding, it is easier for decision makers to assess the alternatives by using language descriptions instead of accurate numerical results. Many methods focus on the transformation between the target information and lingual variables in the site selection problem, such as the triangular fuzzy number [25,28-31], trapezoidal fuzzy number [32-34], 2-tuple linguistic representation model [35,36], intuitionistic fuzzy sets [37], interval valued fuzzy sets [38,39], axiomatic fuzzy set [40] as well as rough sets [41]. Although these methods describe the uncertainty of evaluation indicators in different ways and to different degrees, they focus on the fuzziness rather than on randomness, which is an important component of uncertainty. In the end, the interaction 
relationships between the criteria should be considered and measured reasonably. The commonest methods to determine the weights of criteria in site selection research are shown in Table 2.

Table 2. Methods to determine the weights of the criteria.

\begin{tabular}{|c|c|c|}
\hline Methods & Relevant Studies & Descriptions \\
\hline \multirow{4}{*}{$\begin{array}{l}\text { AHP } \\
\text { Rank correlation } \\
\text { analysis method } \\
\text { FAHP } \\
\text { Fuzzy theory }\end{array}$} & [42-48] & \multirow{4}{*}{$\begin{array}{l}\text { These methods make the independence of the criteria } \\
\text { a connotative presupposition, which obviously cannot } \\
\text { match reality. }\end{array}$} \\
\hline & {$[49,50]$} & \\
\hline & {$[28,30,32]$} & \\
\hline & {$[17,34,36,51]$} & \\
\hline $\begin{array}{l}\text { 2-order additive } \\
\text { fuzzy measure }\end{array}$ & [52] & $\begin{array}{l}\text { (1) The method takes the relativity of the indicators } \\
\text { into consideration. } \\
\text { (2) The computational complexity is quite high, which makes } \\
\text { it difficult to employ in practical applications. }\end{array}$ \\
\hline$\lambda$-fuzzy measure & {$[53,54]$} & $\begin{array}{l}\text { (1) The method takes the relativity of the indicators } \\
\text { into consideration. } \\
\text { (2) The method is too hidebound to measure the correlations, } \\
\text { which would give rise to decreased accuracy and rationality of } \\
\text { the consequences. }\end{array}$ \\
\hline
\end{tabular}

Based on the above analysis, the PROMETHEE method integrated with the cloud model and the ANP method is recommended to make up for the above shortcomings. On the one hand, the cloud model was first described by Li [55], an expert in command automation and artificial intelligence from the Chinese Academy of Engineering. The cloud model comprehensively analyzes the randomness and fuzziness of the uncertainty, which can greatly reduce the loss of useful information. The cloud model has been studied and widely applied in recent years. For instance, Wang [56] proposed a 2nd-order generic normal cloud model and presented the 2nd-order generic forward normal cloud transformation algorithm, Wang [57] proposed some operations of clouds and several new aggregation operators. The fruit fly optimization algorithm [58] and the artificial immune clustering algorithm [59] are combined with the cloud model to improve the convergence performance and solve stochastic problems. Furthermore, the cloud model is applied for risk management [60-64]. On the other hand, the ANP is the most appropriate tool for solving problems that are complicated with inherent relationships among the evaluation criteria [65]. The ANP method is widely employed in research and development for optimal site selection, such as the case of offshore wind farms [66], landfills [67,68], as well as wind power plants [69]. In short, the PROMETHEE method integrated with the cloud model and the ANP method is a suitable and reasonable approach, which should be conducive to exercisable and scientific EVCS site selection decisions.

\section{Analysis of Evaluation Attributes}

Charging station site selection is affected by various factors. An extensive body of literature reveals that the attributes of economic factors and land factors are paid general attention in the site selection research area. Apart from this, numerous aspects of engineering feasibility factors are worthy of serious consideration for convenience and security. In the quest for service availability, a charging station should be located at a place that has convenient traffic conditions and large demand of service. In addition, as an important component of infrastructure, the charging station is directly bound up with the social development, which leads to social factors becoming a significant attribute too. Also, it is necessary to take environmental factors into account for sustainable development in harmony with the environment. Considering of all these attributes simultaneously can ensure comprehensiveness and rationality for the charging stations site selection process.

The attributes considered for site selection of charging stations are therefore: (1) economic factors, (2) engineering feasibility, (3) service availability, (4) social factors (5) environmental factors and (6) land factors. 


\subsection{Economic Factors}

Three sub-criteria related to the economic factors are aggregated as follows:

(1) Construction cost (C11) [17,50,53,54,70-75]: The construction cost, which includes land acquisition cost, any demolition and site preparation costs, facility cost as well as the project investment cost, varies greatly amongst the different regions of China, giving rise to the different degree of appropriateness for the site selection.

(2) Operation and maintenance cost (C12) [17,50,71-75]: It includes all kinds of expenses and amortization of daily operation and maintenance. Operation and maintenance cost is an important criterion as it could have a great influence on the profitability.

(3) Investment payoff period (C13) [17,53,72,75]: It is relevant to cost and operating income. The introduction of investment payoff period makes the evaluation more meaningful for practice.

\subsection{Engineering Feasibility}

Some conventional criteria for engineering feasibility and extraordinary criteria relevant to the charging station location problem are considered synthetically. Three sub-criteria related to the engineering feasibility are aggregated as follows:

(1) Distance from the substation (C21) [50,54,70,75-79]: In the power market this is an important parameter for it is related to power supply reliability, degree of power loss and project cost. The ideal location of the charging station is as close as possible to the substation.

(2) Influence on the power system (C22) [53,70,75-77]: As an important component of medium and low-voltage distribution systems, the charging station could inevitably have an adverse impact on the power stability. As a result, the charging station should be located an area away from the heavy load lines to ensure the secure operation of the distribution network.

(3) Availability of resources (C23) [54,70,71,73,75,77,78,80]: A site which has good availability of construction water and power should be given priority for the purpose of allowing a fast construction schedule.

\subsection{Service Availability}

Three sub-criteria related to the service availability are aggregated as follows:

(1) Convenience of transportation (C31) [34,50,54,71-73,76-78,80-83]: The parameter which contains the condition of main road, the number of lanes and the number of intersections near the charging station, is critical to the realization of high profit and convenience.

(2) Service capability (C32) $[71,73,76,81]$ : It is defined as the daily service volume as well as the maximum number of EV that could get access to the charging service provided by the charging station.

(3) Service radius (C33) [34,50,71,76,80]: On the one hand, it is inappropriate to keep away from the adjacent charging stations for the sake of running capacity of the EV and daily needs of the users. On the other hand, the short distance from the adjacent charging stations is also inapposite for giving rise to the waste of resources.

\subsection{Social Factors}

Three sub-criteria related to the social factors are aggregated as follows:

(1) Possibility of capacity expansion in future (C41) [71,72]. This is a necessary requirement for the reason that expansion of the charging station is an inevitable trend for the sake of economic development and environmental protection.

(2) Attitude of local residents (C42) [17,50,53,54,72,75,80]: It is unavoidable to have negative effects of noise and electromagnetic field due to the construction and operation of the charging station on the residents near the station, so it is preferable to take the attitude of local residents into account. 
(3) Local government support (C43) $[53,54,72,75]$. This attribute contains the subsidy policy, favorable price and tax preferences, which are set to greatly promote the development of EVs.

\subsection{Environmental Factors}

Four sub-criteria related to the environmental factors are aggregated as follows:

(1) Ecological environment influence (C51) $[17,50,53,54,73,75-78,80,84]$. The construction and operation procedures would have many adverse effects on the local vegetation and water, so it is preferable to minimize the extent of the damage.

(2) Availability of space for disposal of waste (C52) [17,80]. Whether the sewage and the solid waste could be dealt with well to reduce pressure on the environment is a pivotal indicator.

(3) Energy-saving benefits (C53) $[17,50,53,54,72,73,75]$. Compared with the internal combustion engine vehicles, the use of EVs would save fuel tremendously. The favorable influence on the environment must be taken into account because of the emission of greenhouse gases and fuel shortages.

(4) Fine particles emission reduction (C54) $[17,50,53,54,73,75]$. This is a unique attribute for China because of the plague of haze which could be greatly relieved by the application and popularization of EVs.

\subsection{Geographical Environment}

Two sub-criteria related to the geographical environment are aggregated as follows:

(1) Topography (C61) $[34,50,53,70,71,76,77,84]$. This has great effect on the safety and stability of the construction. The appropriate site of charging stations should be away from highland and landslide.

(2) Geology and soil type (C62) [50,53,54,71-73,76,80]. These factors have a great effect on the type of the civil engineering necessary and project cost. It is preferable to keep the site away from loose and sandy soil to ensure the safety of the construction.

\section{Methodology}

PROMETHEE is a subgroup of the MCDM methods developed in the early 1980s by Barns et al. [23]. It has been applied in various areas because of its flexibility and ease of use. This study integrates the PROMETHEE method with the cloud model, proposed by Li [18], to develop a new MCDM method for EVCS site selection. The procedure of the new evaluation method is presented in Figure 1 and can be summarized in the following steps:

Step 1: Determine the alternatives, evaluation criteria and form a group of decision makers. The finite set of alternatives is denoted by $A=\left\{a_{1}, a_{2}, \ldots, a_{m}\right\}$, and the set of criteria is denoted by $C=\left\{c_{1}, c_{2}, \ldots, c_{n}\right\}$. Suppose that there are $k$ decision makers.

Step 2: Determine the weight of each criterion. Since there are some internal relations between criteria, ANP [65] is used in this study to calculate the weight of each criterion. Firstly, the decision makers should determine the interdependence relationships among the criteria. Then, the 1-9 scales are employed to make pair-wise comparisons between the criteria. Finally, the Super Decision software is used to work out the weights. Meanwhile, the inconsistency rate should be controlled not to exceed 0.1.

Step 3: Transformation between linguistic variables and clouds. The decision makers express their ratings linguistically, then the linguistic variables should be transformed into a series of clouds. A cloud model is denoted by $Y\left(E_{x}, E_{n}, H_{e}\right)$, where $E_{x}$ is the expectation, $E_{n}$ represents the entropy, and $H_{e}$ means the hyper-entropy. The operations between two clouds can be seen in [57]. 


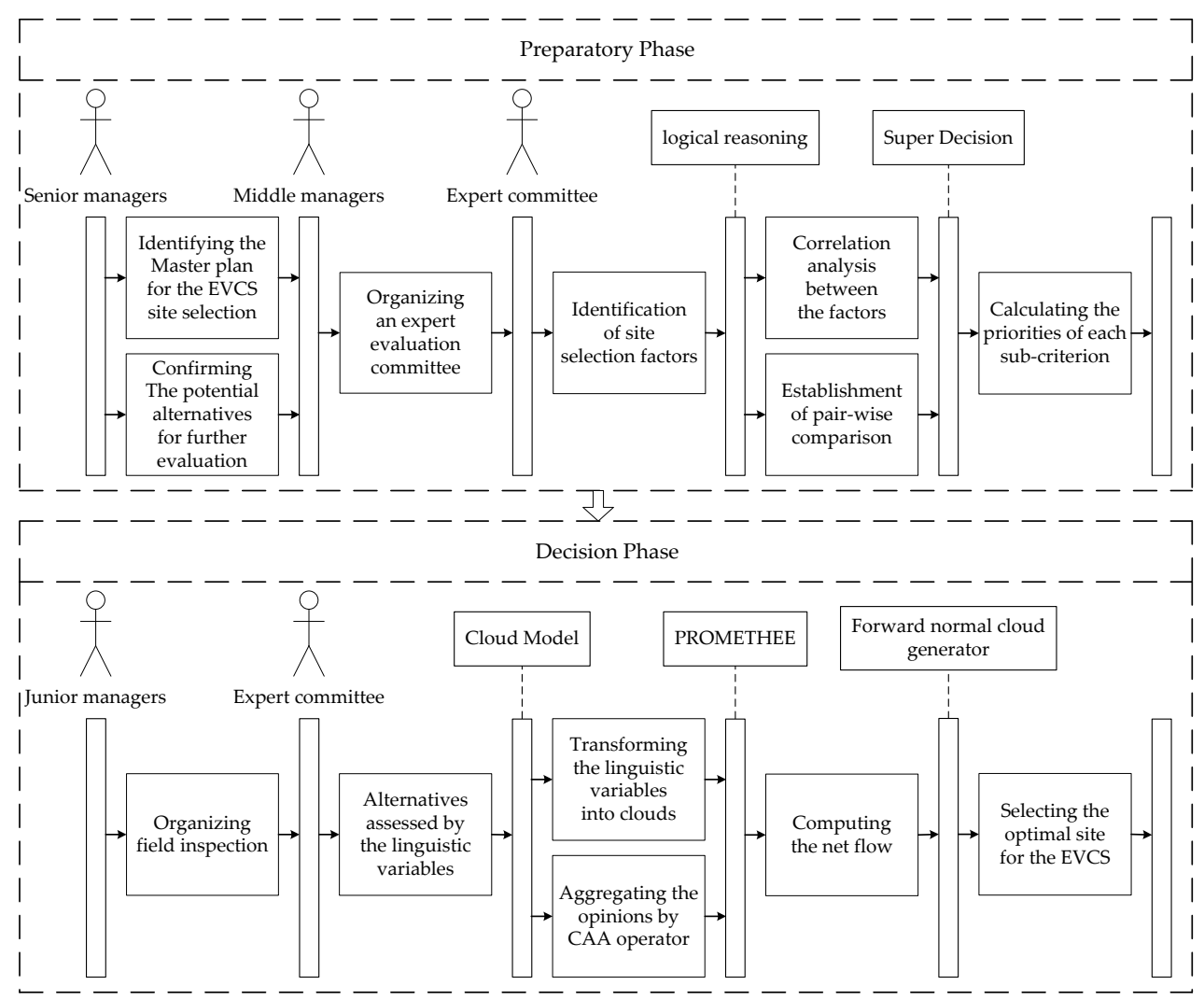

Figure 1. The decision system for the EVCS site selection.

Given the domain $U=\left[X_{\min }, X_{\max }\right]=[0,10]$, the improved linguistic representation model is used, as in the study by Wang et al. [57]. A linguistic term set of seven labels is used to evaluate the performance of each alternative. Table 3 shows the linguistic scales and corresponding clouds for rating of alternatives respectively.

Table 3. Linguistic variables and their corresponding clouds.

\begin{tabular}{cc}
\hline Ratings of Alternatives & Clouds \\
\hline Very poor (VP) & $(0.00,2.959,0.125)$ \\
Poor (P) & $(2.25,2.655,0.226)$ \\
Medium poor (MP) & $(3.85,2.100,0.411)$ \\
Medium (M) & $(5.00,1.922,0.471)$ \\
Medium good (MG) & $(6.15,2.100,0.411)$ \\
Good (G) & $(7.75,2.655,0.226)$ \\
Very good (VG) & $(10.00,2.959,0.125)$ \\
\hline
\end{tabular}

Step 4: Aggregate the criterion values of each alternative. Use the cloud arithmetic average (CAA) operator to aggregate the opinion of each decision maker and obtain the cloud $Y_{j}\left(a_{i}\right)$ which represents the performance value of alternative $a_{i}$ under the criterion $c_{j}$ :

$$
\begin{aligned}
Y_{j}\left(a_{i}\right) & =\frac{1}{k} \otimes\left(Y_{1}+Y_{2}+\ldots+Y_{k}\right) \\
& =\frac{1}{k} \otimes\left(\left(E x_{1}, E n_{1}, H e_{1}\right) \oplus\left(E x_{2}, E n_{2}, H e_{2}\right) \oplus \ldots \oplus\left(E x_{k}, E n_{k}, H e_{k}\right)\right) \\
& =\left(\frac{E x_{1}+E x_{2}+\ldots+E x_{k}}{k}, \sqrt{\frac{E n_{1}^{2}+E n_{2}^{2}+\ldots+E n_{k}^{2}}{k}}, \sqrt{\frac{H e_{1}^{2}+H e_{2}^{2}+\ldots+H e_{n}^{2}}{k}}\right)
\end{aligned}
$$


Step 5: Construct the priority function. PROMETHEE is based on a pair-wise type of relationship, so it is essential to define a suitable priority function. There are six generalized types of priority function and the V-shape function is employed in this study [23]. The V-shape function based on the cloud model to criterion $c_{j}$ can be expressed as follows:

$$
P_{j}(d)= \begin{cases}0 & d \leqslant 0 \\ d / p & 0 \leqslant d \leqslant p \\ 1 & d \geqslant p\end{cases}
$$

where $d$ represents the comparison value of two alternatives under the criterion $c_{j}$, and $p$ is the threshold of strict preference. The priority degree based on the cloud model of alternative $a$ over $b$ to criterion $c_{j}$ is denoted as:

$$
\begin{aligned}
P_{j}(a, b) & =P_{j}\left(Y_{a} \ominus Y_{b}\right) \\
& =P_{j}\left(\left(E x_{a}, E n_{a}, H e_{a}\right) \ominus\left(E x_{b}, E n_{b}, H e_{b}\right)\right) \\
& =\left(P_{j}\left(E x_{a}-E x_{b}\right), P_{j}\left(\sqrt{E n_{a}^{2}+E n_{b}^{2}}\right), P_{j}\left(\sqrt{H e_{a}^{2}+H e_{b}^{2}}\right)\right)
\end{aligned}
$$

Step 6: Determine the preference index. The preference index based on the cloud model is defined as follows:

$$
\begin{aligned}
\Pi(a, b) & =\sum_{j=1}^{n} w_{j} \otimes P_{j}(a, b) \\
& =\left(\sum_{j=1}^{n} w_{j} P_{j}\left(E x_{a}-E x_{b}\right), \sqrt{\sum_{j=1}^{n} w_{j} P_{j}^{2}\left(\sqrt{E n_{a}^{2}+E n_{b}^{2}}\right)}, \sqrt{\sum_{j=1}^{n} w_{j} P_{j}^{2}\left(\sqrt{H e_{a}^{2}+H e_{b}^{2}}\right)}\right) \\
\Pi(b, a) & =\sum_{j=1}^{n} w_{j} \otimes P_{j}(b, a) \\
& =\left(\sum_{j=1}^{n} w_{j} P_{j}\left(E x_{b}-E x_{a}\right), \sqrt{\sum_{j=1}^{n} w_{j} P_{j}^{2}\left(\sqrt{E n_{a}^{2}+E n_{b}^{2}}\right)}, \sqrt{\left.\sum_{j=1}^{n} w_{j} P_{j}^{2}\left(\sqrt{H e_{a}^{2}+H e_{b}^{2}}\right)\right)}\right.
\end{aligned}
$$

In the equations above $\mathrm{w}_{\mathrm{j}}$ is the weight of criterion $c_{\mathrm{j}}$. $\Pi(a, b)$ represents the preference degree that $\mathrm{a}$ is preferred to $\mathrm{b}$, while $\Pi(b, a)$ is the preference degree that $\mathrm{b}$ is preferred to $\mathrm{a}$.

Step 7: Determine the positive leaving flow $\phi^{+}(a)$. As an index for the strength of alternative $a$, the positive leaving flow is calculated as follows:

$$
\phi^{+}(a)=\sum_{\substack{b \in A \\ b \neq a}}^{m} \Pi(a, b)
$$

Step 8: Determine the negative entering flow $\phi^{-}(a)$. As an index for the weakness of alternative $a$, the negative entering flow is calculated as follows:

$$
\phi^{-}(a)=\sum_{\substack{b \in A \\ b \neq a}}^{m} \Pi(b, a)
$$

Step 9: Compute the net flow $\phi^{\text {net }}(a)$ :

$$
\phi^{n e t}(a)=\phi^{+}(a)-\phi^{-}(a)
$$


Step 10: Compare the cloud of each alternative for ranking. The three parameters $E_{x}, E_{n}, H_{e}$ and the number of cloud drops $n$ are given to compare the cloud theoretically by forward normal cloud generator as described in [55]. Then the expected value $\hat{s}$ of cloud $A$ is denoted as follows:

$$
\hat{s}(A)=(1 / n) \sum_{i=1}^{n} x_{i} y_{i}
$$

in which, $x_{i}$ is a cloud drop in the domain, and $y_{i}$ is the degree of certainty of $x_{i}$. Given the two clouds $A$ and $B$, if $\hat{s}(A) \geqslant \hat{s}(B)$, then $A \geqslant B$.

\section{A Case Study}

In order to improve the air quality, Beijing has put forward in the Thirteenth Five-Year plan its view that the new resources and clean-energy vehicles of the whole city should reach 20 million by 2020. Based on the company's development strategy and market requirements, a Chinese electricity company wants to build a charging station for EVs in Beijing.

According to the development planning of Beijing which is " $N$ sites driven by the three ring roads" to set up the demonstration, the third to the fifth ring road are selected to build the charging stations with the higher priority. Considering the coordination of the charging stations with the urban road network and power grid development planning, four sites located in the Daxing district, Haidian district, Shijingshan district and Chaoyang district, respectively, are determined as the alternatives by the senior managers, as shown in Figure 2. The alternatives, which are denoted as A1, A2, A3 and A4, possess the typical characteristics of the North China Plain and are suitable for construction.

In order to achieve maximize the economic and social efficiency, the middle managers of the company decide to invite an expert evaluation committee to help them select the most appropriate site for the EV charging station.

First of all, the group of decision makers consists of five kinds of experts who are authorities in the fields of economy, engineering, environment, electrical power system and transportation system, respectively. Three experts who should be of similarly high prestige are invited in each field. The experts from different academic background play important roles in two aspects. One is in consultation with each other to determine the valuable attributes within the certain backgrounds and the relative degree of importance considering the interactions among various factors. The other is to assess the performance of the alternatives in the form of linguistic variables with respect to sub-criteria.

After that, the evaluation index system is determined by the decision maker group. On account of the alternatives being much alike in land factors and government support (government subsidies would cover $30 \%$ of the investment in equipment), sub-criteria C43 and C6 can be ignored, leaving the six criteria and 15 sub-criteria shown in Table 4.

After determining the criteria and alternatives in the early planning stage, the network structure which is the first step of ANP should be obtained. Brainstorming is held with the group members to determine the interdependencies and pair-wise comparisons among the criteria. At first, the opinion of each expert should be collected separately, and then, several collective discussions focusing on the divergence would be held until agreement has been reached. The final mutual influence concern of the factors is shown in Table 4 based on the consensus. The symbol " $\sqrt{ }$ " means that the criterion in the row would have an effect on the factor in the column. 


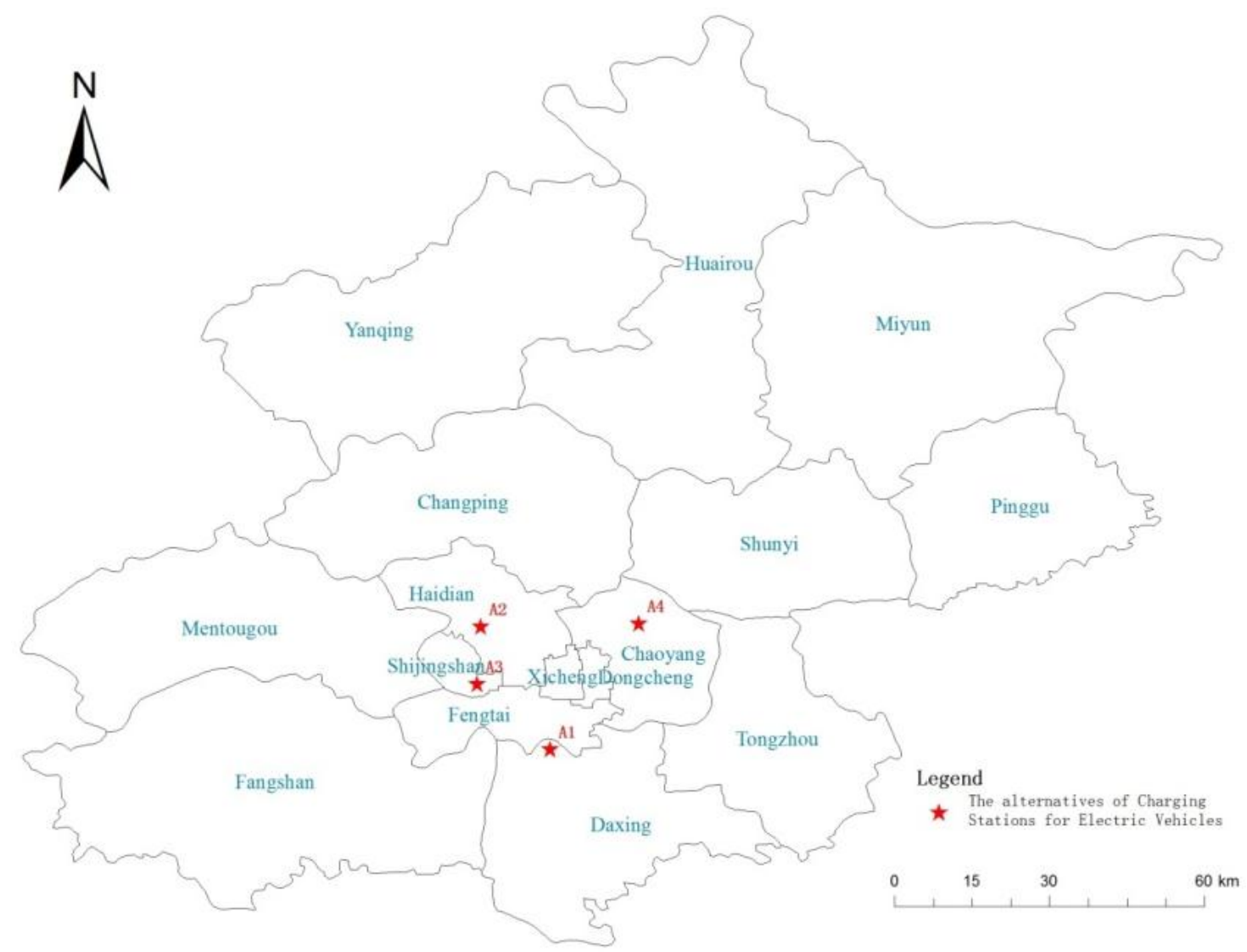

Figure 2. The geographical positions of the potential sites.

Table 4. Mutual influence concerns of the factors.

\begin{tabular}{|c|c|c|c|c|c|c|c|c|c|c|c|c|c|c|c|}
\hline & \multicolumn{3}{|c|}{$\begin{array}{l}\text { Economic } \\
\text { Factors }\end{array}$} & \multicolumn{3}{|c|}{$\begin{array}{l}\text { Engineering } \\
\text { Feasibility }\end{array}$} & \multicolumn{3}{|c|}{$\begin{array}{c}\text { Service } \\
\text { Availability }\end{array}$} & \multicolumn{2}{|c|}{$\begin{array}{c}\text { Social } \\
\text { Factors }\end{array}$} & \multicolumn{4}{|c|}{$\begin{array}{c}\text { Environmental } \\
\text { Factors }\end{array}$} \\
\hline & $\mathrm{C} 11$ & $\mathrm{C} 12$ & $\mathrm{C} 13$ & C21 & $\mathrm{C} 22$ & $\mathrm{C} 23$ & C31 & C32 & $\mathrm{C} 33$ & C41 & $\mathrm{C} 42$ & C51 & C52 & C53 & C54 \\
\hline C11 & & & $\sqrt{ }$ & & & $\sqrt{ }$ & & & & $\sqrt{ }$ & & & & & \\
\hline C12 & & & $\sqrt{ }$ & $\sqrt{ }$ & $\sqrt{ }$ & & & & & & & & $\sqrt{ }$ & & \\
\hline C13 & & & & $\sqrt{ }$ & & & $\sqrt{ }$ & & & & & & & & \\
\hline C21 & & $\sqrt{ }$ & & & $\sqrt{ }$ & & & & & & & & & & \\
\hline $\mathrm{C} 22$ & & $\sqrt{ }$ & & & & & & $\sqrt{ }$ & & $\sqrt{ }$ & & & & & \\
\hline $\mathrm{C} 23$ & $\sqrt{ }$ & & & & & & $\sqrt{ }$ & & & & & & & & \\
\hline C31 & $\sqrt{ }$ & & $\sqrt{ }$ & & & $\sqrt{ }$ & & $\sqrt{ }$ & $\sqrt{ }$ & & & & & $\sqrt{ }$ & $\sqrt{ }$ \\
\hline C32 & $\sqrt{ }$ & $\sqrt{ }$ & $\sqrt{ }$ & & $\sqrt{ }$ & & & & $\sqrt{ }$ & & & & & $\sqrt{ }$ & \\
\hline C33 & & & & & & & & $\sqrt{ }$ & & & & & & $\sqrt{ }$ & $\sqrt{ }$ \\
\hline C41 & & & & $\sqrt{ }$ & $\sqrt{ }$ & $\sqrt{ }$ & $\sqrt{ }$ & $\sqrt{ }$ & $\sqrt{ }$ & & & $\sqrt{ }$ & $\sqrt{ }$ & $\sqrt{ }$ & $\sqrt{ }$ \\
\hline C42 & $\sqrt{ }$ & $\sqrt{ }$ & $\sqrt{ }$ & $\sqrt{ }$ & & & & & & $\sqrt{ }$ & & & & & \\
\hline C51 & $\sqrt{ }$ & & & & & & & & & & & & & & \\
\hline C52 & & $\sqrt{ }$ & & & & & & & & & $\sqrt{ }$ & $\sqrt{ }$ & & & \\
\hline C53 & & & & & & & & & & & & & & & \\
\hline C54 & & & & & & & & & & & & & & & \\
\hline
\end{tabular}

After confirming the interactional relationship, the degree of importance of each sub-criterion is determined by using pair-wise comparisons based on the experience and logical reasoning of the experts. A specialized software package is used to calculate the priorities of each sub-criterion after assuring the consistency of each comparison matrix. Finally, the priorities of the criteria are shown in Table 5. 
Table 5. The weights of the criteria.

\begin{tabular}{lcc}
\hline & Sub-Criterion & Weights \\
\hline C11 & Construction cost & 0.0850 \\
C12 & Operation and maintenance cost & 0.0783 \\
C13 & Investment payoff period & 0.0921 \\
C21 & Distance from the substation & 0.0463 \\
C22 & Influence on the power system & 0.0466 \\
C23 & Availability of resources & 0.0515 \\
C31 & Convenience of transportation & 0.1319 \\
C32 & Service capability & 0.0747 \\
C33 & Service radius & 0.0536 \\
C41 & Possibility of future capacity & 0.0273 \\
C42 & expansion & 0.0099 \\
C51 & Attitude of local residents & 0.0468 \\
C52 & Ecological environment influence & 0.0655 \\
C53 & Availability of space for waste & 0.0853 \\
C54 & disposal & 0.1052 \\
\hline
\end{tabular}

Since the weights of the sub-criteria are found, the questionnaires are designed to collect the performance linguistic information of the alternatives. The field inspection should be organized by the junior managers for more information about the alternatives. Each expert would take charge of the partial evaluation which is relevant to their research field and disregard the others. Then the questionnaires are completed by the experts separately, and the results are listed in Table 6.

Table 6. Linguistic ratings for the sub-criteria of four site alternatives.

\begin{tabular}{|c|c|c|c|c|c|c|c|c|c|c|c|c|}
\hline & \multicolumn{3}{|c|}{ A1 } & \multicolumn{3}{|c|}{$\mathrm{A} 2$} & \multicolumn{3}{|c|}{ A3 } & \multicolumn{3}{|c|}{ A4 } \\
\hline & DM1 & DM2 & DM3 & DM1 & DM2 & DM3 & DM1 & DM2 & DM3 & DM1 & DM2 & DM3 \\
\hline C11 & $\mathrm{P}$ & MP & $\mathrm{MP}$ & $M$ & $\mathrm{M}$ & $\mathrm{MP}$ & MG & $\mathrm{M}$ & $M$ & MG & $G$ & MG \\
\hline C12 & MG & G & $\mathrm{MG}$ & G & VG & G & G & G & MG & VG & G & VG \\
\hline C13 & $\mathrm{P}$ & VP & VP & MP & VP & $\mathrm{P}$ & $\mathrm{MP}$ & $\mathrm{P}$ & VP & $\mathrm{P}$ & $\mathrm{MP}$ & MP \\
\hline C21 & MG & G & $\mathrm{MG}$ & G & MG & G & VG & G & $\mathrm{G}$ & VG & VG & $\mathrm{G}$ \\
\hline C22 & $\mathrm{VP}$ & MP & $\mathrm{MP}$ & MG & $\mathrm{MP}$ & MG & $\mathrm{MP}$ & MG & $\mathrm{MP}$ & MG & VG & MG \\
\hline $\mathrm{C} 23$ & $\mathrm{P}$ & $\mathrm{P}$ & $\mathrm{VP}$ & $\mathrm{P}$ & G & $\mathrm{G}$ & $\mathrm{G}$ & $\mathrm{P}$ & $\mathrm{P}$ & VG & G & G \\
\hline C31 & $\mathrm{MP}$ & $\mathrm{P}$ & $\mathrm{P}$ & G & MG & MG & G & MG & G & G & VG & G \\
\hline C32 & $\mathrm{M}$ & M & MP & M & MG & $\mathrm{M}$ & MG & MG & G & G & $\mathrm{G}$ & VG \\
\hline C33 & $\mathrm{M}$ & MP & $\mathrm{MP}$ & M & MG & $\mathrm{M}$ & $\mathrm{M}$ & $\mathrm{M}$ & $\mathrm{MP}$ & MG & MG & M \\
\hline C41 & MP & $\mathrm{M}$ & $\mathrm{MP}$ & M & $\mathrm{M}$ & $\mathrm{MP}$ & M & MG & $\mathrm{M}$ & $\mathrm{M}$ & MG & MG \\
\hline C42 & $\mathrm{M}$ & MG & MG & G & G & MG & MG & G & MG & VG & G & G \\
\hline C51 & MG & G & $\mathrm{MG}$ & MG & $\mathrm{G}$ & $\mathrm{G}$ & $\mathrm{G}$ & VG & $\mathrm{G}$ & $\mathrm{G}$ & VG & VG \\
\hline C52 & MG & M & $\mathrm{M}$ & MG & G & G & G & MG & MG & VG & G & $\mathrm{G}$ \\
\hline C53 & $\mathrm{P}$ & $\mathrm{P}$ & VP & $\mathrm{P}$ & MP & $\mathrm{MP}$ & MP & $\mathrm{M}$ & $\mathrm{MP}$ & $\mathrm{M}$ & MG & MG \\
\hline C54 & $\mathrm{MP}$ & $\mathrm{M}$ & $\mathrm{M}$ & $\mathrm{M}$ & M & MG & $\mathrm{MP}$ & M & $\mathrm{MP}$ & MG & G & G \\
\hline
\end{tabular}

Then according to Table 3 in Step 3, the linguistic variables are transformed into a series of clouds. The CAA operator which is elaborated in Equation (1) is used to aggregate the opinion of each decision maker and obtain the integrated cloud, where $k=3$ and the calculation of $Y_{13}\left(a_{2}\right)$ is illustrated as an example. By that analogy, the results are shown in Table 7.

$$
\begin{aligned}
Y_{13}\left(a_{2}\right) & =\frac{1}{3} \otimes((3.850,2.100,0.411) \oplus(0.000,2.959,0.125) \oplus(2.250,2.655,0.226)) \\
& =(2.033,2.596,0.280)
\end{aligned}
$$


Table 7. The aggregation cloud for the sub-criteria of four site alternatives.

\begin{tabular}{ccccc}
\hline & A1 & A2 & A3 & A4 \\
\hline C11 & $(3.317,2.300,0.360)$ & $(4.617,1.983,0.452)$ & $(5.383,1.983,0.452)$ & $(6.683,2.300,0.360)$ \\
C12 & $(6.683,2.300,0.360)$ & $(8.500,2.760,0.198)$ & $(7.217,2.484,0.301)$ & $(9.250,2.861,0.166)$ \\
C13 & $(0.750,2.861,0.166)$ & $(2.033,2.596,0.280)$ & $(2.033,2.596,0.280)$ & $(3.317,2.300,0.360)$ \\
C21 & $(6.683,2.300,0.360)$ & $(7.217,2.484,0.301)$ & $(8.500,2.760,0.198)$ & $(9.250,2.861,0.166)$ \\
C22 & $(2.567,2.420,0.343)$ & $(5.383,2.100,0.411)$ & $(4.617,2.100,0.411)$ & $(7.433,2.420,0.343)$ \\
C23 & $(1.500,2.760,0.198)$ & $(5.917,2.655,0.226)$ & $(4.083,2.655,0.226)$ & $(8.500,2.760,0.198)$ \\
C31 & $(2.783,2.484,0.301)$ & $(7.217,2.484,0.301)$ & $(6.683,2.300,0.36)$ & $(8.500,2.760,0.198)$ \\
C32 & $(4.617,1.983,0.452)$ & $(5.383,1.983,0.452)$ & $(6.683,2.300,0.360)$ & $(8.500,2.760,0.198)$ \\
C33 & $(4.233,2.042,0.432)$ & $(5.383,1.983,0.452)$ & $(4.617,1.983,0.452)$ & $(5.767,2.042,0.432)$ \\
C41 & $(4.233,2.042,0.432)$ & $(4.617,1.983,0.452)$ & $(5.383,1.983,0.452)$ & $(5.767,2.042,0.432)$ \\
C42 & $(5.767,2.042,0.432)$ & $(7.217,2.484,0.301)$ & $(6.683,2.300,0.360)$ & $(8.500,2.760,0.198)$ \\
C51 & $(6.683,2.300,0.360)$ & $(7.217,2.484,0.301)$ & $(8.500,2.760,0.198)$ & $(9.250,2.861,0.166)$ \\
C52 & $(5.383,1.983,0.452)$ & $(7.217,2.484,0.301)$ & $(6.683,2.300,0.360)$ & $(8.500,2.760,0.198)$ \\
C53 & $(1.500,2.760,0.198)$ & $(3.317,2.300,0.360)$ & $(4.233,2.042,0.432)$ & $(5.767,2.042,0.432)$ \\
C54 & $(4.617,1.983,0.452)$ & $(5.383,1.983,0.452)$ & $(4.233,2.042,0.432)$ & $(7.217,2.484,0.301)$ \\
\hline
\end{tabular}

For finding the appropriate priority function of each criterion, a few of seminars are held with the group of experts. All of the priority functions are examined and the conformity to the criteria of site selection for charging stations is assessed. After intense debate, it is decided to employ the V-shape function for all the criteria and the parameter value of $p$ is set to 16 for all the criteria.

The priority degree based on the cloud model of four alternatives to each criterion is obtained according to the Equations (2) and (3) in Step 5. For instance, the process of determining $P_{23}\left(a_{2}, a_{3}\right)$ could be shown as follows:

$$
\begin{aligned}
P_{23}\left(a_{2}, a_{3}\right) & =P_{23}((5.917,2.655,0.226) \ominus(4.083,2.655,0.226)) \\
& =\left(P_{23}(1.833), P_{21}(3.755), P_{21}(0.320)\right) \\
& =\left(\frac{1.833}{16}, \frac{3.755}{\sqrt{16}}, \frac{0.320}{\sqrt{16}}\right)=(0.115,0.939,0.080)
\end{aligned}
$$

Then by following Equations (4) and (5) described in Step 6, the preference index of the four alternatives could be obtained, as shown in Table 8.

Table 8. The preference index of the four alternatives.

\begin{tabular}{ccccc}
\hline & A1 & A2 & A3 & A4 \\
\hline A1 & & $(0.000,0.830,0.126)$ & $(0.003,0.826,0.127)$ & $(0.000,0.869,0.115)$ \\
A2 & $(0.116,0.830,0.126)$ & & $(0.031,0.820,0.128)$ & $(0.000,0.864,0.116)$ \\
A3 & $(0.111,0.826,0.127)$ & $(0.024,0.820,0.128)$ & & $(0.000,0.859,0.118)$ \\
A4 & $(0.224,0.869,0.115)$ & $(0.108,0.864,0.116)$ & $(0.115,0.859,0.118)$ & \\
\hline
\end{tabular}

Further, the net flows on the basis of the positive leaving flow and the negative entering flow could be obtained by using Equations (6) to (8) in Steps 7 to 9. For instance, the process of determining $\phi^{\text {net }}\left(a_{2}\right)$ could be shown as follows.

$$
\begin{aligned}
\phi^{\text {net }}\left(a_{2}\right) & =((0.116,0.830,0.126) \oplus(0.031,0.820,0.128) \oplus(0.000,0.864,0.116)) \\
& \ominus((0.000,0.830,0.126) \oplus(0.024,0.820,0.128) \oplus(0.108,0.864,0.116)) \\
& =(0.148,1.452,0.214) \ominus(0.132,1.452,0.214) \\
& =(0.016,2.054,0.303)
\end{aligned}
$$


The results are shown in Table 9.

Table 9. The positive leaving flow and the negative entering flow.

\begin{tabular}{cccc}
\hline $\boldsymbol{a}$ & $\boldsymbol{\phi}^{+}(\boldsymbol{a})$ & $\boldsymbol{\phi}^{-}(\boldsymbol{a})$ & $\boldsymbol{\phi}^{\text {net }}(\boldsymbol{a})$ \\
\hline A1 & $(0.003,1.458,0.213)$ & $(0.452,1.458,0.213)$ & $(-0.450,2.062,0.302)$ \\
A2 & $(0.148,1.452,0.214)$ & $(0.132,1.452,0.214)$ & $(0.016,2.054,0.303)$ \\
A3 & $(0.135,1.447,0.216)$ & $(0.149,1.447,0.216)$ & $(-0.014,2.046,0.305)$ \\
A4 & $(0.447,1.497,0.202)$ & $(0.000,1.497,0.202)$ & $(0.447,2.117,0.285)$ \\
\hline
\end{tabular}

Finally, according to Equation (9) in Step 10, the expected value $\hat{s}$ of the cloud is repeated five times for stability. The results are shown in Table 10. The sequence of the four alternatives can be obtained through the average value $\hat{s}$, and they are ranked as follows: A4 $>$ A2 $>$ A3 $>$ A1.

Table 10. The expected values of the clouds.

\begin{tabular}{ccccccc}
\hline & 1st & 2st & 3st & 4st & 5st & Average \\
\hline$\hat{s}$ (A1) & -0.3210 & -0.3123 & -0.3181 & -0.3125 & -0.3226 & -0.3173 \\
$\hat{s}$ (A2) & 0.0102 & 0.0136 & 0.0173 & 0.0104 & 0.0281 & 0.0159 \\
$\hat{s}$ (A3) & -0.0180 & -0.0229 & -0.0222 & -0.0184 & -0.0180 & -0.0199 \\
$\hat{s}$ (A4) & 0.2918 & 0.3038 & 0.3167 & 0.3284 & 0.3058 & 0.3093 \\
\hline
\end{tabular}

\section{Discussion}

\subsection{Comparative Analysis}

In order to prove the feasibility and validity of the proposed PROMETHEE based on the cloud model, a comparison with the results of fuzzy PROMETHEE is analyzed. The analysis is conducted on the basis of the same illustrative example.

Likewise, the first step is to transform the linguistic variables into the corresponding triangular fuzzy numbers. The study of conversion between the linguistic term set of seven labels with the fuzzy numbers has been conducted by Birol [25]. The results are shown in Table 11.

Table 11. Linguistic variables and the corresponding fuzzy numbers.

\begin{tabular}{cc}
\hline Ratings of Alternatives & Triangular Fuzzy Numbers $(l, m, u)$ \\
\hline Very poor $(\mathrm{VP})$ & $(0.00,0.00,0.15)$ \\
Poor $(\mathrm{P})$ & $(0.00,0.15,0.30)$ \\
Medium poor (MP) & $(0.15,0.30,0.50)$ \\
Medium (M) & $(0.30,0.50,0.65)$ \\
Medium good (MG) & $(0.50,0.65,0.80)$ \\
Good $(\mathrm{G})$ & $(0.65,0.80,1.00)$ \\
Very good $(\mathrm{VG})$ & $(0.80,1.00,1.00)$ \\
\hline
\end{tabular}

Then the opinions of the decision makers are aggregated by using the fuzzy operations as shown in Equation (10):

$$
f_{j}(a)=\left(\min \left(l_{i}\right),\left(\sum_{i=1}^{k} m_{i}\right) / k, \max \left(u_{i}\right)\right)
$$

In this equation, $k$ means the number of the decision makes, and $i=1,2, \ldots, k$. The comprehensive performance value of alternative $a$ under the criterion $c_{j}$ is obtained and shown in Table 12: 
Table 12. Fuzzy PROMETHEE criteria evaluation matrix.

\begin{tabular}{ccccc}
\hline & A1 & A2 & A3 & A4 \\
\hline C11 & $(0.000,0.250,0.500)$ & $(0.150,0.433,0.650)$ & $(0.300,0.550,0.800)$ & $(0.500,0.700,1.000)$ \\
C12 & $(0.500,0.700,1.000)$ & $(0.650,0.867,1.000)$ & $(0.500,0.750,1.000)$ & $(0.650,0.933,1.000)$ \\
C13 & $(0.000,0.050,0.300)$ & $(0.000,0.150,0.500)$ & $(0.000,0.150,0.500)$ & $(0.000,0.250,0.500)$ \\
C21 & $(0.500,0.700,1.000)$ & $(0.500,0.750,1.000)$ & $(0.650,0.867,1.000)$ & $(0.650,0.933,1.000)$ \\
C22 & $(0.000,0.200,0.500)$ & $(0.150,0.533,0.800)$ & $(0.150,0.417,0.800)$ & $(0.500,0.767,1.000)$ \\
C23 & $(0.000,0.100,0.300)$ & $(0.000,0.583,1.000)$ & $(0.000,0.367,1.000)$ & $(0.650,0.867,1.000)$ \\
C31 & $(0.000,0.200,0.500)$ & $(0.500,0.750,1.000)$ & $(0.500,0.700,1.000)$ & $(0.650,0.867,1.000)$ \\
C32 & $(0.150,0.433,0.650)$ & $(0.300,0.550,0.800)$ & $(0.500,0.700,1.000)$ & $(0.650,0.867,1.000)$ \\
C33 & $(0.150,0.367,0.650)$ & $(0.300,0.550,0.800)$ & $(0.150,0.433,0.650)$ & $(0.300,0.600,0.800)$ \\
C41 & $(0.150,0.367,0.650)$ & $(0.150,0.433,0.650)$ & $(0.300,0.550,0.800)$ & $(0.300,0.600,0.800)$ \\
C42 & $(0.300,0.600,0.800)$ & $(0.500,0.750,1.000)$ & $(0.500,0.700,1.000)$ & $(0.650,0.867,1.000)$ \\
C51 & $(0.500,0.700,1.000)$ & $(0.500,0.750,1.000)$ & $(0.650,0.867,1.000)$ & $(0.650,0.933,1.000)$ \\
C52 & $(0.300,0.550,0.800)$ & $(0.500,0.750,1.000)$ & $(0.500,0.700,1.000)$ & $(0.650,0.867,1.000)$ \\
C53 & $(0.000,0.100,0.300)$ & $(0.000,0.250,0.500)$ & $(0.150,0.367,0.650)$ & $(0.300,0.600,0.800)$ \\
C54 & $(0.150,0.433,0.650)$ & $(0.300,0.550,0.800)$ & $(0.150,0.367,0.650)$ & $(0.500,0.750,1.000)$ \\
\hline
\end{tabular}

For the same reason, the V-shape function is employed as the priority function in this step, and $p$ is set to 1. After a series of calculations, the preference index of the four alternatives could be obtained, as shown in Table 13. Further, the net flows on the basis of the positive leaving flow and the negative entering flow could be obtained, and the results are listed in Table 14.

Table 13. The preference index of the four alternatives.

\begin{tabular}{ccccc}
\hline & A1 & A2 & A3 & A4 \\
\hline A1 & & $(0.000,0.216,0.669)$ & $(0.000,0.206,0.689)$ & $(0.038,0.401,0.773)$ \\
A2 & $(0.000,0.000,0.307)$ & & $(0.000,0.039,0.542)$ & $(0.000,0.186,0.626)$ \\
A3 & $(0.000,0.007,0.284)$ & $(0.000,0.055,0.498)$ & & $(0.000,0.202,0.603)$ \\
A4 & $(0.000,0.000,0.143)$ & $(0.000,0.000,0.320)$ & $(0.000,0.000,0.340)$ & \\
\hline
\end{tabular}

Table 14. The positive leaving flow and the negative entering flow.

\begin{tabular}{ccccc}
\hline $\boldsymbol{a}$ & $\boldsymbol{\phi}^{+}(\boldsymbol{a})$ & $\boldsymbol{\phi}^{-}(\boldsymbol{a})$ & $\boldsymbol{\phi}^{\text {net }}(\boldsymbol{a})$ & Defuzzification \\
\hline A1 & $(0.000,0.007,0.733)$ & $(0.038,0.823,2.131)$ & $(-0.038,-0.816$, & -0.767 \\
A2 & $(0.000,0.271,1.486)$ & $(0.000,0.224,1.474)$ & $(0.000,0.046,0.012)$ & 0.026 \\
A3 & $(0.000,0.245,1.571)$ & $(0.000,0.264,1.385)$ & $(0.000,-0.020$, & 0.037 \\
A4 & $(0.038,0.789,2.002)$ & $(0.000,0.000,0.803)$ & $(0.038,0.789,1.199)$ & 0.704 \\
\hline
\end{tabular}

Finally, the defuzzification operator is defined as Equation (11) to convert the triangular fuzzy numbers into crisp values, and the results are shown in Table 14 . The sequence of the four alternatives could be determined as $\mathrm{A} 4>\mathrm{A} 3>\mathrm{A} 2>\mathrm{A} 1$ :

$$
\widetilde{\phi}(a)=(l+2 m+u) / 4
$$

The results of PROMETHEE based on the cloud model and fuzzy numbers are shown in Table 15.

Table 15. Comparison between different algorithms.

\begin{tabular}{ll}
\hline \multicolumn{1}{c}{ Algorithm } & Ranking Results \\
\hline PROMETHEE based on the fuzzy numbers & A4 $>$ A3 $>$ A2 $>$ A1 \\
PROMETHEE based on the cloud model & A4 $>$ A2 $>$ A3 $>$ A1 \\
\hline
\end{tabular}


From Table 15 it can be seen that the main difference lies in the ranking of A2 and A3. The main reasons for this could be interpreted as follows:

Traditional fuzzy linguistic functions give standards to judge the priority of evaluation alternatives by means of considering the average level as the only true measure, which gives rise to the characteristics of one-sidedness and roughness of the model. As the example above showed, the average level of $\mathrm{A} 3$ is higher than that of $\mathrm{A} 2$, so the result $\mathrm{A} 3>\mathrm{A} 2$ could be obtained. Unlike the traditional fuzzy linguistic function, the cloud model thinks about not only the average level denoted by $E_{x}$ but also the fluctuation and stability which are indicated by $E_{n}$ and $H_{e}$, respectively. The linguistic scale of the traditional fuzzy linguistic function is uniform, while the cloud model employs the multi-granular linguistic evaluation scale, which is far more accurate to reflect the actual features of the psychological sense. As a result, the average level of A2 is higher than that of A3, and $E_{n 2}>E_{n 3}, H_{e 2}<H_{e 3}$ in the PROMETHEE method based on the cloud model. Beyond that, the cloud model takes the randomness of the evaluation value into account, which resolves the divergence among the decision makers and the distortion could thus be counteracted. Considering all of the reasons above, the final ranking derived from the PROMETHEE based on the cloud model, A4 $>$ A2 $>$ A3 $>$ A1 is more accurate and credible than the results obtained by the method based on the fuzzy numbers.

On another dimension, A2 is more superior for the EVCS site selection than A3 in the following four aspects: firstly, the alternative A2 is located in Haidian District, which is the center of culture, science and technology of Beijing. Many renowned universities are distributed in the Haidian District, such as the Peking University, as well as Tsinghua University. Moreover, the famous photography spots like the Summer Palace as well as the Fragrant Hill, the global icon of Haidian, are there. As environment worsens, the EV charging stations may be even more desperately needed than in $\mathrm{A} 3$ as a result of the emergence of haze, which is reflected in the sub-criterion C54. Secondly, A2 could dispose of the waste created by the charging station in a more scientific manner, because of its advances in technology, which reduces the risk of repeated pollution of the environment. Thirdly, the operational and maintenance cost is a long-term development expenditure, which is directly relevant to the future development of the charging stations. To compare with the alternative of A3, A2 is more superior in this aspect. Last but not the least, the residents of A2 are responding to the promotion of charging station construction positively, which contributes to forming a strong application demonstration effect. In brief, the alternative A2 is more suitable for the construction of the charging station compared with A3.

\subsection{Sensitivity Analysis}

A good robustness is an essential element that an evaluation method must have to make it a successful one. A sensitivity analysis is performed to test whether the results would qualitatively change if the index weights fluctuate. The situations where the weight of each sub-criterion increases by $10 \%, 20 \%, 30 \%$ and reduces by $10 \%, 20 \%, 30 \%$ are compared with the weights derived from the expert judgments and the ANP method. The overall consequences of the sensitivity analysis are that there is no difference, as A4 and A2 are always the best and the second best alternatives for the EVCS site selection, while A1 is the lowest ranked location for the EVCS site selection. These consistent results are shown in Figure 3. Based on these consistent results, it could be concluded that the evaluation method proposed in this paper has good stability to choose the best within the potential alternatives. 


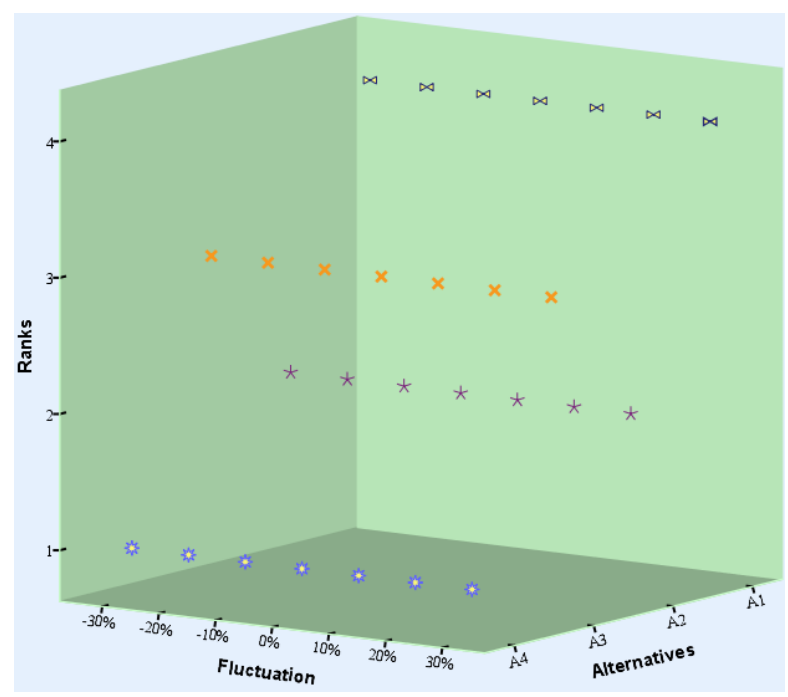

Figure 3. The sensitivity analysis results. $\bowtie \rtimes \times$ represent the ranks of alternatives A1, A2, A3 and A4, respectively, in the situations that the weight of each sub-criterion increases by $10 \%, 20 \%, 30 \%$ and reduces by $10 \%, 20 \%, 30 \%$ compared with the weight derived from the expert judgments and the ANP method.

\section{Conclusions}

In recent years, with the severity of the energy shortage and air pollution situation, there has been a great focus on EVs on account of their reduction of particulate matter (PM) 2.5 emissions and high energy efficiency. In accordance with this, the site selection for EVCS, which is a multi-objective decision making problem, is hugely important from the perspective of harmonious and sustainable development. However, some flaws and inadequacies underlying the traditional MCDM methods could give rise to inaccurate and irrational decision results.

In this paper, the PROMETHEE method-based decision system combined with the cloud model, which can make up for many flaws and inadequacies of the traditional MCDM methods is proposed for EVCS site selection. Firstly, it can fully describe the uncertainty of information. Secondly, it takes the relationships between the indexes into consideration, and measures them it in a way that makes sense. The last, the decision system is easy to use, which contributes to improving the flexibility and confidence of the managers. It's worth mentioning that the decision system illustrates the labor division of different level managers, which could greatly promote management and strengthen the accuracy and feasibility.

Finally, a case from Beijing is brought forward for validating the feasibility and validity of the proposed decision system. A comparison analysis and sensitivity analysis are conducted to prove the superiority and stability of the proposed decision system. All these endeavors provide evidence that the PROMETHEE method-based decision system combined with the cloud model for EVCS site selection is feasible, reasonable, as well as stable, which should also provide more confidence and visibility for decision makers.

Acknowledgments: Project supported by the Fundamental Research Funds for the National Nature Science Foundation of China (No.71271085), the Central Universities (No.2015XS27).

Author Contributions: The initial design of the optimal EVCS site selection framework was done by Yunna Wu. Meng Yang established the model, calculated the result and drafted the paper. Haobo Zhang gave some useful suggestions for this work and helped revise the manuscript. Kaifeng Chen provided the idea of cloud model and gave instructions to the research. Finally, Yang Wang formatted the manuscript for submission.

Conflicts of Interest: The authors declare no conflict of interest. 


\section{References}

1. Gao, J.P.; Zhang, Y.Z.; He, H.W. A real-time joint estimator for model parameters and state of charge of lithium-ion batteries in electric vehicles. Energies 2015, 8, 8594-8612. [CrossRef]

2. Hou, C.; Wang, H.W.; Ouyang, M.Y. Battery sizing for plug-in hybrid electric vehicles in Beijing: A TCO model based analysis. Energies 2014, 7, 5374-5399. [CrossRef]

3. Liu, Z.T.; He, H.W. Model-based sensor fault diagnosis of a lithium-ion battery in electric vehicles. Energies 2015, 8, 6509-6527. [CrossRef]

4. Zhang, S.; Zhang, C.M.; Xiong, R.; Zhou, W. Study on the optimal charging strategy for lithium-ion batteries used in electric vehicles. Energies 2014, 7, 6783-6797. [CrossRef]

5. Han, P.; Wang, J.K.; Han, Y.H.; Li, Y. Resident plug-in electric vehicle charging modeling and scheduling mechanism in the smart grid. Math. Probl. Eng. 2014, 2014, 540624. [CrossRef]

6. Ju, L.W.; Tan, Z.F.; Li, H.H.; Yu, X.B.; Zhang, H.J. Multiobjective synergistic scheduling optimization model for wind power and plug-in hybrid electric vehicles under different grid-connected modes. Math. Probl. Eng. 2014, 2014, 179583. [CrossRef]

7. Yang, Y.Q.; Zhang, W.G.; Jiang, J.C.; Huang, M.; Niu, L.Y. Optimal scheduling of a battery energy storage system with electric vehicles' auxiliary for a distribution network with renewable energy integration. Energies 2015, 8, 10718-10735. [CrossRef]

8. Alonso, M.; Amaris, H.; Germain, J.G.; Galan, J.M. Optimal charging scheduling of electric vehicles in smart grids by heuristic algorithms. Energies 2014, 7, 2449-2475. [CrossRef]

9. De Cauwer, C.; Van Mierlo, J.; Coosemans, T. Energy consumption prediction for electric vehicles based on real-world data. Energies 2015, 8, 8573-8593. [CrossRef]

10. Lang, J.L.; Cheng, S.Y.; Zhou, Y.; Zhao, B.B.; Wang, H.Y.; Zhang, S.J. Energy and environmental implications of hybrid and electric vehicles in China. Energies 2013, 6, 2663-2685. [CrossRef]

11. Wang, H.W.; Zhang, X.B.; Ouyang, M.G. Energy consumption of electric vehicles based on real-world driving patterns: A case study of Beijing. Appl. Energy 2015, 157, 710-719. [CrossRef]

12. Yuan, X.M.; Li, L.L.; Gou, H.D.; Dong, T.T. Energy and environmental impact of battery electric vehicle range in China. Appl. Energy 2015, 157, 75-84. [CrossRef]

13. Schill, W.P.; Gerbaulet, C. Power system impacts of electric vehicles in Germany: Charging with coal or renewables? Appl. Energy 2015, 156, 185-196. [CrossRef]

14. Aziz, M.; Oda, T.; Mitani, T.; Watanabe, Y.; Kashiwagi, T. Utilization of electric vehicles and their used batteries for peak-load shifting. Energies 2015, 8, 3720-3738. [CrossRef]

15. You, P.S.; Hsieh, Y.C. A hybrid heuristic approach to the problem of the location of vehicle charging stations. Comput. Ind. Eng. 2014, 70, 195-204. [CrossRef]

16. Chung, S.H.; Kwon, C.H. Multi-period planning for electric car charging station locations: A case of Korean expressways. Eur. J. Oper. Res. 2015, 242, 677-687. [CrossRef]

17. Guo, S.; Zhao, H.R. Optimal site selection of electric vehicle charging station by using fuzzy TOPSIS based on sustainability perspective. Appl. Energy 2015, 158, 390-402. [CrossRef]

18. Li, D.; Liu, C.; DU, Y. Artificial intelligence with uncertainty. Software 2004, 15, 1583-1594.

19. Liao, H.C.; Xu, Z.S. Multi-criteria decision making with intuitionistic fuzzy PROMETHEE. J. Intell. Fuzzy Syst. 2014, 27, 1703-1717.

20. Betrie, G.D.; Sadiq, R.; Morin, K.A.; Tesfamariam, S. Selection of remedial alternatives for mine sites: A multicriteria decision analysis approach. J. Environ. Manag. 2013, 119, 36-46. [CrossRef] [PubMed]

21. Peng, A.H.; Xiao, X.M. Material selection using promethee combined with analytic network process under hybrid environment. Mater. Des. 2013, 47, 643-652. [CrossRef]

22. Chen, T.Y. An interval type-2 fuzzy PROMETHEE method using a likelihood-based outranking comparison approach. Inf. Fusion 2015, 25, 105-120. [CrossRef]

23. Brans, J.P.; Vincke, P.; Mareschal, B. How to select and how to rank projects: The PROMETHEE method. Eur. J. Oper. Res. 1986, 24, 228-238. [CrossRef]

24. Behzadian, M.; Kazemadeh, R.B.; Albadvi, A.; Aghdasi, M. Promethee: A comprehensive literature review on methodologies and applications. Eur. J. Oper. Res. 2010, 200, 198-215. [CrossRef]

25. Elevli, B. Logistics freight center locations decision by using fuzzy-PROMETHEE. Transport 2014, 29, 412-418. [CrossRef] 
26. Chen, T.Y. A PROMETHEE-based outranking method for multiple criteria decision analysis with interval type-2 fuzzy sets. Soft Comput. 2014, 18, 923-940. [CrossRef]

27. Mousavi, S.M.; Tavakkoli-Moghaddam, R.; Heydar, M.; Ebrahimnejad, S. Multi-criteria decision making for plant location selection: An integrated Delphi-AHP-PROMETHEE methodology. Arab. J. Sci. Eng. 2012, 38, 1255-1268. [CrossRef]

28. Beskese, A.; Demir, H.H.; Ozcan, H.K.; Okten, H.E. Landfill site selection using fuzzy ahp and fuzzy TOPSIS: A case study for Istanbul. Environ. Earth Sci. 2015, 73, 3513-3521. [CrossRef]

29. Ding, J.F.; Chou, C.C. An evaluation model of quantitative and qualitative fuzzy multi-criteria decision-making approach for location selection of transshipment ports. Math. Probl. Eng. 2013, 2013, 783105. [CrossRef]

30. Ghoseiri, K.; Lessan, J. Waste disposal site selection using an analytic hierarchal pairwise comparison and electre approaches under fuzzy environment. J. Intell. Fuzzy Syst. 2014, 26, 693-704.

31. Kabir, G.; Sumi, R.S. Power substation location selection using fuzzy analytic hierarchy process and promethee: A case study from Bangladesh. Energy 2014, 72, 717-730. [CrossRef]

32. Ardeshir, A.; Mohseni, N.; Behzadian, K.; Errington, M. Selection of a bridge construction site using fuzzy analytical hierarchy process in Geographic Information Systems. Arab. J. Sci. Eng. 2014, 39, 4405-4420. [CrossRef]

33. Chou, C.C.; Yu, K.W. Application of a new hybrid fuzzy AHP model to the location choice. Math. Probl. Eng. 2013, 4, 601-622. [CrossRef]

34. Kurt, Ü. The fuzzy topsis and generalized Choquet fuzzy integral algorithm for nuclear power plant site selection-A case study from Turkey. J. Nucl. Sci. Technol. 2014, 51, 1241-1255. [CrossRef]

35. Liu, H.C.; You, J.X.; Chen, Y.Z.; Fan, X.J. Site selection in municipal solid waste management with extended vikor method under fuzzy environment. Environ. Earth Sci. 2014, 72, 4179-4189. [CrossRef]

36. Liu, H.C.; You, J.X.; Fan, X.J.; Chen, Y.Z. Site selection in waste management by the Vikor method using linguistic assessment. Appl. Soft Comput. 2014, 21, 453-461. [CrossRef]

37. Devi, K.; Yadav, S.P. A multicriteria intuitionistic fuzzy group decision making for plant location selection with Electre method. Int. J. Adv. Manuf. Technol. 2013, 66, 1219-1229. [CrossRef]

38. Bai, X.J.; Liu, Y. Minimum risk facility location-allocation problem with type-2 fuzzy variables. Sci. World J. 2014, 2014, 472623. [CrossRef] [PubMed]

39. Mokhtarian, M.N.; Sadi-nezhad, S.; Makui, A. A new flexible and reliable interval valued fuzzy Vikor method based on uncertainty risk reduction in decision making process: An application for determining a suitable location for digging some pits for municipal wet waste landfill. Comput. Ind. Eng. 2014, 78, 213-233. [CrossRef]

40. Li, Y.; Liu, X.D.; Chen, Y. Selection of logistics center location using axiomatic fuzzy set and TOPSIS methodology in logistics management. Expert Syst. Appl. 2011, 38, 7901-7908. [CrossRef]

41. Liu, S.; Chan, F.T.S.; Chung, S.H. A study of distribution center location based on the rough sets and interactive multi-objective fuzzy decision theory. Robot. Comput. Integr. Manuf. 2011, 27, 426-433. [CrossRef]

42. Alavi, N.; Goudarzi, G.; Babaei, A.A.; Jaafarzadeh, N.; Hosseinzadeh, M. Municipal solid waste landfill site selection with geographic information systems and analytical hierarchy process: A case study in Mahshahr County, Iran. Waste Manag. Res. 2013, 31, 98-105. [CrossRef] [PubMed]

43. Capilla, J.A.J.; Carrion, J.A.; Alameda-Hernandez, E. Optimal site selection for upper reservoirs in pump-back systems, using geographical information systems and multicriteria analysis. Renew. Energy 2016, 86, 429-440. [CrossRef]

44. El Baba, M.; Kayastha, P.; De Smedt, F. Landfill site selection using multi-criteria evaluation in the GIS interface: A case study from the Gaza Strip, Palestine. Arab. J. Geosci. 2015, 8, 7499-7513. [CrossRef]

45. Garcia, J.L.; Alvarado, A.; Blanco, J.; Jimenez, E.; Maldonado, A.A.; Cortes, G. Multi-attribute evaluation and selection of sites for agricultural product warehouses based on an analytic hierarchy process. Comput. Electron. Agric. 2014, 100, 60-69. [CrossRef]

46. Kumar, S.; Hassan, M.I. Selection of a landfill site for solid waste management: An application of AHP and spatial analyst tool. J. Indian Soc. Remote 2013, 41, 45-56. [CrossRef]

47. Shahabi, H.; Keihanfard, S.; Bin Ahmad, B.; Amiri, M.J.T. Evaluating boolean, AHP and WLC methods for the selection of waste landfill sites using GIS and satellite images. Environ. Earth Sci. 2014, 71, 4221-4233. [CrossRef] 
48. Yal, G.P.; Akgun, H. Landfill site selection utilizing TOPSIS methodology and clay liner geotechnical characterization: A case study for Ankara, Turkey. Bull. Eng. Geol. Environ. 2014, 73, 369-388. [CrossRef]

49. Jelokhani-Niaraki, M.; Malczewskil, J. A group multicriteria spatial decision support system for parking site selection problem: A case study. Land Use Policy 2015, 42, 492-508. [CrossRef]

50. Wu, Y.N.; Yang, Y.S.; Feng, T.T.; Kong, L.N.; Liu, W.; Fu, L.J. Macro-site selection of wind/solar hybrid power station based on ideal matter-element model. Int. J. Electr. Power 2013, 50, 76-84.

51. Liu, C.; Chen, Z.H.; Gong, Y.Y. Site selection of emergency material warehouse under fuzzy environment. J. Cent. South Univ. 2013, 20, 1610-1615. [CrossRef]

52. Wu, J.Z.; Zhang, Q.A. 2-order additive fuzzy measure identification method based on diamond pairwise comparison and maximum entropy principle. Fuzzy Optim. Decis. Mak. 2010, 9, 435-453. [CrossRef]

53. Wu, Y.N.; Geng, S.; Xu, H.; Zhang, H.B. Study of decision framework of wind farm project plan selection under intuitionistic fuzzy set and fuzzy measure environment. Energy Convers. Manag. 2014, 87, $274-284$. [CrossRef]

54. Wu, Y.N.; Geng, S.; Zhang, H.B.; Gao, M. Decision framework of solar thermal power plant site selection based on linguistic Choquet operator. Appl. Energy 2014, 136, 303-311. [CrossRef]

55. Li, D.Y.; Liu, C.Y.; Gan, W.Y. A new cognitive model: Cloud model. Int. J. Intell. Syst. 2009, 24, 357-375. [CrossRef]

56. Wang, G.Y.; Xu, C.L.; Li, D.Y. Generic normal cloud model. Inf. Sci. 2014, 280, 1-15. [CrossRef]

57. Wang, J.Q.; Lu, P.; Zhang, H.Y.; Chen, X.H. Method of multi-criteria group decision-making based on cloud aggregation operators with linguistic information. Inf. Sci. 2014, 274, 177-191. [CrossRef]

58. Wu, L.H.; Zuo, C.L.; Zhang, H.Q. A cloud model based fruit fly optimization algorithm. Knowl. Based Syst. 2015, 89, 603-617. [CrossRef]

59. Zhang, R.L.; Shan, M.Y.; Liu, X.H.; Zhang, L.H. A novel fuzzy hybrid quantum artificial immune clustering algorithm based on cloud model. Eng. Appl. Artif. Intell. 2014, 35, 1-13. [CrossRef]

60. Li, C.B.; Qi, Z.Q.; Feng, X. A multi-risks group evaluation method for the informatization project under linguistic environment. J. Intell. Fuzzy Syst. 2014, 26, 1581-1592.

61. Liu, Z.B.; Shao, J.F.; Xu, W.Y.; Xu, F. Comprehensive stability evaluation of rock slope using the cloud model-based approach. Rock Mech. Rock Eng. 2014, 47, 2239-2252. [CrossRef]

62. Zhang, L.M.; Wu, X.G.; Chen, Q.Q.; Skibniewski, M.J.; Zhong, J.B. Developing a cloud model based risk assessment methodology for tunnel-induced damage to existing pipelines. Stoch. Environ. Res. Risk Assess. 2015, 29, 513-526. [CrossRef]

63. Zhang, L.M.; Wu, X.G.; Ding, L.Y.; Skibniewski, M.J. A novel model for risk assessment of adjacent buildings in tunneling environments. Build. Environ. 2013, 65, 185-194. [CrossRef]

64. Zhao, H.R.; Li, N.N. Risk evaluation of a UHV power transmission construction project based on a cloud model and fce method for sustainability. Sustainability 2015, 7, 2885-2914. [CrossRef]

65. Saaty, T.L. Decision Making with Dependence and Feedback: The Analytic Network Process; RWS Publishering: Pittsburgh, PA, USA, 1996.

66. Fetanat, A.; Khorasaninejad, E. A novel hybrid MCDM approach for offshore wind farm site selection: A case study of Iran. Ocean Coast. Manag. 2015, 109, 17-28. [CrossRef]

67. Afzali, A.; Sabri, S.; Rashid, M.; Samani, J.M.V.; Ludin, A.N.M. Inter-municipal landfill site selection using analytic network process. Water Resour. Manag. 2014, 28, 2179-2194. [CrossRef]

68. Isalou, A.A.; Zamani, V.; Shahmoradi, B.; Alizadeh, H. Landfill site selection using integrated fuzzy logic and analytic network process (F-ANP). Environ. Earth Sci. 2013, 68, 1745-1755. [CrossRef]

69. Azizi, A.; Malekmohammadi, B.; Jafari, H.R.; Nasiri, H.; Parsa, V.A. Land suitability assessment for wind power plant site selection using ANP-DEMATEL in a GIS environment: Case study of Ardabil Province, Iran. Environ. Monit. Assess. 2014, 186, 6695-6709. [CrossRef] [PubMed]

70. Azoumah, Y.; Ramde, E.W.; Tapsoba, G.; Thiam, S. Siting guidelines for concentrating solar power plants in the Sahel: Case study of Burkina Faso. Sol. Energy 2010, 84, 1545-1553. [CrossRef]

71. Choudhary, D.; Shankar, R. An steep-fuzzy AHP-topsis framework for evaluation and selection of thermal power plant location: A case study from India. Energy 2012, 42, 510-521. [CrossRef]

72. Dong, J.; Feng, T.T.; Yang, Y.S.; Ma, Y. Macro-site selection of wind/solar hybrid power station based on Electre-II. Renew. Sustain. Energy Rev. 2014, 35, 194-204. 
73. Ekmekcioglu, M.; Kaya, T.; Kahraman, C. Fuzzy multicriteria disposal method and site selection for municipal solid waste. Waste Manag. 2010, 30, 1729-1736. [CrossRef] [PubMed]

74. Erol, I.; Sencer, S.; Ozmen, A.; Searcy, C. Fuzzy MCDM framework for locating a nuclear power plant in Turkey. Energy Policy 2014, 67, 186-197. [CrossRef]

75. Yunna, W.; Geng, S. Multi-criteria decision making on selection of solar-wind hybrid power station location: A case of China. Energy Convers. Manag. 2014, 81, 527-533. [CrossRef]

76. Abudeif, A.M.; Moneim, A.A.A.; Farrag, A.F. Multicriteria decision analysis based on analytic hierarchy process in GIS environment for siting nuclear power plant in Egypt. Ann. Nucl. Energy 2015, 75, 682-692. [CrossRef]

77. Gorsevski, P.V.; Cathcart, S.C.; Mirzaei, G.; Jamali, M.M.; Ye, X.Y.; Gomezdelcampo, E. A group-based spatial decision support system for wind farm site selection in Northwest Ohio. Energy Policy 2013, 55, 374-385. [CrossRef]

78. Tsiourtis, N.X. Criteria and procedure for selecting a site for a desalination plant. Desalination 2008, 221, 114-125. [CrossRef]

79. Vagiona, D.G.; Karanikolas, N.M. A multicriteria approach to evaluate offshore wind farms siting in Greece. Glob. NEST J. 2012, 14, 235-243.

80. Ekmekcioglu, M.; Kutlu, A.C.; Kahraman, C. A fuzzy multi-criteria SWOT analysis: An application to nuclear power plant site selection. Int. J. Comput. Intell. Syst. 2011, 4, 583-595. [CrossRef]

81. Kuo, M.S. Optimal location selection for an international distribution center by using a new hybrid method. Expert Syst. Appl. 2011, 38, 7208-7221. [CrossRef]

82. Latinopoulos, D.; Kechagia, K. A GIS-based multi-criteria evaluation for wind farm site selection. A regional scale application in Greece. Renew. Energ 2015, 78, 550-560. [CrossRef]

83. Xiao, J.H.; Yao, Z.Y.; Qu, J.J.; Sun, J.H. Research on an optimal site selection model for desert photovoltaic power plants based on analytic hierarchy process and geographic information system. J. Renew. Sustain. Energy 2013, 5, 023132. [CrossRef]

84. Ji, Y.; Huang, G.H.; Sun, W. Risk assessment of hydropower stations through an integrated fuzzy entropy-weight multiple criteria decision making method: A case study of the Xiangxi River. Expert Syst. Appl. 2015, 42, 5380-5389. [CrossRef] 